\title{
Estimated effective dose of CT-guided percutaneous cryoablation of liver tumors
}

\section{Citation}

Park, Byung Kwan, Paul R. Morrison, Servet Tatli, Usha Govindarajulu, Kemal Tuncali, Phil Judy, Paul B. Shyn, and Stuart G. Silverman. 2012. "Estimated Effective Dose of CT-Guided Percutaneous Cryoablation of Liver Tumors." European Journal of Radiology 81 (8) (August): 1702-1706. doi:10.1016/j.ejrad.2011.04.067.

\section{Published Version}

10.1016/j.ejrad.2011.04.067

\section{Permanent link}

http://nrs.harvard.edu/urn-3:HUL.InstRepos:33896764

\section{Terms of Use}

This article was downloaded from Harvard University's DASH repository, and is made available under the terms and conditions applicable to Other Posted Material, as set forth at http:// nrs.harvard.edu/urn-3:HUL.InstRepos:dash.current.terms-of-use\#LAA

\section{Share Your Story}

The Harvard community has made this article openly available.

Please share how this access benefits you. Submit a story.

\section{Accessibility}




\title{
Estimated effective dose of CT-guided percutaneous cryoablation of liver tumors
}

\author{
Byung Kwan Parka, ${ }^{\star}$, Paul R. Morrison ${ }^{b}$, Servet Tatli ${ }^{\mathrm{b}}$, Usha Govindarajuluc ${ }^{\mathrm{c}}$, Kemal \\ Tuncali $^{\mathrm{b}}$, Phil Judy ${ }^{\mathrm{b}}$, Paul B. Shyn ${ }^{\mathrm{b}}$, and Stuart G. Silverman ${ }^{\mathrm{b}}$ \\ aDepartment of Radiology, Samsung Medical Center, Sungkyunkwan University School of \\ Medicine, Seoul, Republic of Korea \\ bDepartment of Radiology, Brigham \& Women's Hospital, 75 Francis Street, Boston, MA 02115, \\ United States \\ 'Department of Medicine, Brigham \& Women's Hospital, 75 Francis Street, Boston, MA 02115, \\ United States
}

\begin{abstract}
Purpose-To estimate effective dose during CT-guided cryoablation of liver tumors, and to assess which procedural factors contribute most to dose.

Materials and methods-Our institutional review board approved this retrospective, HIPAAcompliant study. A total of 20 CT-guided percutaneous liver tumor cryoablation procedures were performed in 18 patients. Effective dose was determined by multiplying the dose length product for each CT scan obtained during the procedure by a conversion factor $(0.015 \mathrm{mSv} / \mathrm{mGy}-\mathrm{cm})$, and calculating the sum for each phase of the procedure: planning, targeting, monitoring, and postablation survey. Effective dose of each phase was compared using a repeated measures analysis. Using Spearman correlation coefficients, effective doses were correlated with procedural factors including number of scans, ratio of targeting distance to tumor size, anesthesia type, number of applicators, performance of ancillary procedures (hydrodissection and biopsy), and use of CT fluoroscopy.
\end{abstract}

Results-Effective dose per procedure was $72 \pm 18 \mathrm{mSv}$. The effective dose of targeting (37.5 \pm $12.5 \mathrm{mSv}$ ) was the largest component compared to the effective dose of the planning phase (4.8 \pm $2.2 \mathrm{mSv})$, the monitoring phase $(25.5 \pm 6.8 \mathrm{mSv})$, and the post-ablation survey $(4.1 \pm 1.9 \mathrm{mSv})$ phase $(p<0.05)$. Effective dose correlated positively only with the number of scans $(p<0.01)$.

Conclusions-The effective dose of CT-guided percutaneous cryoablation of liver tumors can be substantial. Reducing the number of scans during the procedure is likely to have the greatest effect on lowering dose.

\section{Keywords}

Interventional oncology; Radiation; Cryoablation; Liver; Cancer

\footnotetext{
项his publication was made possible by Grant Number RR019703 from NIH.

(C) 2011 Elsevier Ireland Ltd. All rights reserved.

*Corresponding author at: Department of Radiology and Center for Imaging Science, Samsung Medical Center, Sungkyunkwan University School of Medicine, 50 Ilwon-dong Kangnam-ku, Seoul 135-710, Republic of Korea. Tel.: +82 23410 6457; fax: +82 2 3410 0084.rapark@skku.edu..
} 


\section{Introduction}

Percutaneous radiofrequency ablation (RFA) and cryoablation are minimally invasive treatment alternatives for managing liver tumors in patients who are unable to undergo surgical resection [1-8]. CT is used often as a guidance modality for ablation because of its favorable spatial and contrast resolution and, in part, because of radiologists' familiarity with the use of CT for guiding percutaneous needle biopsies and drainages. During cryoablation, CT can provide excellent visualization of the iceball in the liver, whereas CT monitoring of heat during hepatic RFA is not feasible. Like other interventional procedures, several intermittent $\mathrm{CT}$ scans are required during an ablation procedure and thus, there is the potential for high radiation doses.

To our knowledge, there are few reports that have focused on radiation dose of CT-guided $\mathrm{RF}$ ablation; there are none on cryoablation $[9,10]$. We performed this study to estimate effective dose of CT-guided cryoablation of liver tumors, and to assess which procedural factors contribute most to dose.

\section{Materials and methods}

\subsection{Patients}

Our institutional review board approved this retrospective, HIPAA-compliant study; patient informed consent was waived. Between December 2006 and December 2007, 29 cryoablations on liver tumors were performed. Of the 29 , nine were conducted to treat two or more tumors in the same procedure and therefore were excluded from this study so as to yield a homogeneous population of procedures in which a single tumor was treated during each procedure. As a result, the study population consisted of 20 CT-guided cryoablation procedures during which a solitary liver tumor was treated in 18 patients $(12 \mathrm{men}$ and six women; age range, $44-88$ years; mean age, 61.2 years). Of these 18 patients, 16 had a single procedure and two had two procedures each. One patient had two hepatic masses and underwent two ablation procedures at different times. The other patient had one tumor ablated during the first procedure; the same tumor was retreated during the second procedure.

A diagnosis was obtained via a percutaneous biopsy in all patients, either in a separate CTguided procedure several days prior to $(n=13)$ or during $(n=7)$ the cryoablation procedure. Diagnoses consisted of 14 metastases and four primary tumors. Hepatic metastases originated from cancers of the colon $(n=5)$, ovary $(n=3)$, breast $(n=2)$, and one each from the kidney, tonsil, Cowper's gland, and lung. Primary hepatic tumors included three hepatocellular carcinomas and one cancer consisting of both hepatocellular carcinoma and cholangiocarcinoma. Hepatic tumors were located in segment $7(n=5)$, segment $6(n=4)$, segment $8(n=3)$, segment $4(n=2)$, segment $2 / 3(n=2)$, segment $2(n=1)$, segment $5(n=$ $1)$, segment $4 / 8(n=1)$, or segment $7 / 8(n=1)$. Tumor size was determined by measuring the maximum diameter of the tumor on contrast-enhanced CT scan or MRI examination performed prior to the cryoablation procedure. The mean maximum diameter of hepatic tumors was $3.1 \pm 1.5 \mathrm{~cm}(1.4-7.3 \mathrm{~cm})$.

\subsection{CT-guided cryoablation procedures}

Imaging for all cryoablation procedures was obtained with a 40-channel multi-detector CT scanner (Sensation Open, Siemens Medical Solutions, Forchheim, Germany). Automatic tube current modulation (Care Dose4D, Siemens Medical Solutions) was routinely applied for all spiral scans. Procedures were performed under monitored anesthesia care $(n=15)$ or general anesthesia $(n=5)$, in either supine $(n=19)$ or right anterior oblique $(n=1)$ position 
by a team consisting of an attending abdominal interventional radiologist and an abdominal interventional radiology fellow.

Unenhanced CT scans (spiral CT acquisition or as CT fluoroscopy) were acquired intermittently to image the tumor and surrounding anatomy during each of the four phases of the procedure that included planning, targeting, monitoring, and a post-ablation survey.

2.2.1. Planning phase-One or more planning CT scans (mean, 1.3; range, 1-3 scans) were performed with a surface grid in place to image the tumor and surrounding anatomy and to plan applicator insertion with respect to an appropriate skin entry site, insertion angle, and depth. The technical factors of CT acquisitions in this phase were the following: 120 $\mathrm{kVp}, 115-192 \mathrm{mAs}, 0.85$ pitch, $0.5 \mathrm{~s}$ rotation, and $24 \times 1.2 \mathrm{~mm}$ collimation. The mean $Z$ axis length of these scans was $16.0 \mathrm{~cm}$ (range, $12.5-26.5 \mathrm{~cm}$ ).

2.2.2. Targeting phase-Unenhanced $\mathrm{CT}$ scans, with additional CT fluoroscopy during 18 of the 20 procedures, were obtained during targeting to guide the placement of one or more 22 gauge reference needles, and subsequent placement in tandem fashion of multiple 17 gauge cryoablation applicators (mean, 3.9; range, 3-7; Galil Medical, Yokneam, Israel) placed using tandem trocar technique. Multiple applicators were placed with the goal of achieving an iceball large enough to freeze the entire tumor with a $1 \mathrm{~cm}$ margin. The targeting phase also included placing additional 22G fine needles (Chiba Biopsy Needle, Cook Medical, Bloomington, IN) for biopsy in seven procedures. Hydrodissection was performed in two patients to displace bowel away from the ablation zone. Hydrodissection was accomplished with the injection of $200-350 \mathrm{~cm}^{3}$ (mean, $275 \mathrm{~cm}^{3}$ ) of normal saline via a 22 gauge needle. The technical factors of CT acquisitions for the conventional (nonfluoroscopy) CT scans included: $120 \mathrm{kVp}, 102-197 \mathrm{mAs}$, and $24 \times 1.2 \mathrm{~mm}$ collimation. The mean $Z$-axis coverage was $10.4 \mathrm{~cm}$ (range, 4-29 $\mathrm{cm}$ ). The technical factors for CT fluoroscopy scans included: $80-120 \mathrm{kVp}, 30-50 \mathrm{mAs}, 0.85 \mathrm{pitch}, 0.5 \mathrm{~s}$ rotation, and $1.2 \mathrm{~mm}$ collimation.

2.2.3. Monitoring phase-After the cryoablation applicators were placed, two freezethaw cycles (15-min freeze and 10-min thaw each) were performed. A CT scan to include the iceball was performed approximately every 3 min during the freeze to monitor iceball growth. Monitoring was used to be sure the tumor was completely frozen and/or to protect adjacent critical structures. The technical factors of these $\mathrm{CT}$ acquisitions included: 120 $\mathrm{kVp}, 98-197 \mathrm{mAs}, 0.85 \mathrm{pitch}, 0.5 \mathrm{~s}$ rotation, and $24 \times 1.2 \mathrm{~mm}$ collimation. The mean $Z$-axis coverage was $13.1 \mathrm{~cm}$ (range, $5-29 \mathrm{~cm}$ ).

2.2.4. Post-ablation survey phase-After the treatment was completed, all cryoablation applicators were removed, and one or more unenhanced CT scans were obtained to survey the treated tumor and surrounding structures to determine whether the ablation was complete and to identify complications. The technical factors of CT acquisitions were the following: $120 \mathrm{kVp}, 117-190 \mathrm{mAs}, 0.85$ pitch, $0.5 \mathrm{~s}$ rotation, and $24 \times$ $5 \mathrm{~mm}$ collimation. The mean $Z$-axis coverage was $29.5 \mathrm{~cm}$ (range, $5.0-71 \mathrm{~cm}$ ).

\subsection{Effective dose}

The effective dose (mSv) for each scan was determined by multiplying the dose length product (DLP, in $\mathrm{mGy}-\mathrm{cm}$ ) for each scan by a normalized-conversion factor for the abdomen $(0.015 \mathrm{mSv} / \mathrm{mGy}-\mathrm{cm})$ [11-13]. The effective dose for each phase (planning, targeting, monitoring, and post-ablation survey) was calculated by summing the effective dose for each CT scan performed during each phase. Total effective dose was calculated by summing the effective doses for each phase. 
Effective doses for each phase were compared to determine which phase contributed most. To assess which factors contributed most for each procedure, we recorded the following variables: total number of scans for each cryoablation procedure, ratio of targeting distance to tumor size, anesthesia type (general anesthesia or monitored anesthesia care), number of cryoablation applicators, whether hydrodissection or biopsy was performed, and whether CT fluoroscopy was used. We correlated these variables with effective dose for each ablation procedure. The ratio of targeting distance to tumor size was a general measure of technical difficulty: the larger the ratio, the more difficult the tumor was to target [14]. Cryoablation applicators were placed deeply enough to encompass the most distant margin of the tumor. The targeting distance was measured from the skin entry site to the most distant margin of the tumor on the planning CT scan; tumor size was determined using the preprocedural diagnostic MRI exam.

\subsection{Statistical analysis}

Boxplots of the effective dose for each phase of the cryoablation procedure were created. Spearman correlation analysis was used to estimate the correlation between effective dose and the number of scans, the ratio of targeting distance to tumor size, the number of applicators, hydrodissection, biopsy, anesthesia type, and use of CT fluoroscopy.

In a separate analysis, both effective dose and number of scans were modeled separately in a mixed model in which measurements of effective dose and number of scans were repeated for each phase and for each patient. From each mixed model, we obtained least square adjusted mean values of effective dose and number of scans, and made comparisons among them to assess whether or not they were significantly different between phases. All statistical analyses were conducted at the 0.05 level of significance. Data analyses were performed with commercially available software (SAS V9.1, Cary, NC and SPSS for Microsoft Windows, version 11.0, Chicago, IL).

\section{Results}

Total effective dose (mean \pm standard deviation) and effective dose range per procedure were calculated as $72 \pm 18 \mathrm{mSv}$ (46-117 mSv) (Table 1) (Fig. 1). The mean effective doses of planning, targeting, monitoring, and post-ablation survey phases were $4.8 \pm 2.2 \mathrm{mSv}$ (2$10 \mathrm{mSv}), 37.5 \pm 12.5 \mathrm{mSv}(25-67 \mathrm{mSv}), 25.5 \pm 6.8 \mathrm{mSv}(14-42 \mathrm{mSv})$, and $4.1 \pm 1.9 \mathrm{mSv}$ (2-8 mSv), respectively (Fig. 2). From the repeated measures model for effective doses, least square mean comparisons showed that effective dose for each phase were significantly different from each other $(p<0.0001)$ except for the planning and post-ablation survey phases (Table 2). The mean effective dose incurred during targeting accounted for $51.3 \%$ of the total dose incurred during the entire ablation procedure.

Effective dose for each ablation procedure correlated significantly only with the number of scans (coefficient, $0.66 ; p<0.0015$ ). The mean number of scans was $30.1 \pm 5.5$ scans (1944 scans). Using the repeated measures model for the number of scans, least square mean comparisons showed that the mean number of scans obtained during each phase was significantly different from each other $(p<0.0001)$ except for the planning and post-ablation survey phases. The greatest number of scans were obtained during the targeting phase (mean, 16.3 scans; range, 7-29 scans), followed by the number obtained during monitoring (mean, 11.5 scans; range, 7-15 scans), planning (mean, 1.3 scans; range, 1-3 scans), and the post-ablation survey (mean, 1.1 scans; range, 1-2 scans) (Table 2).

No significant correlation was found between effective dose and the ratio of targeting distance to tumor size, anesthesia type, the number of applicators, hydrodissection, biopsy, and use of CT fluoroscopy (coefficient, -0.08 to $0.45 ; p>0.05$ ). The mean targeting 
distance was $11.8 \pm 3.0 \mathrm{~cm}(6.8-17.6 \mathrm{~cm})$ and therefore, the mean ratio of targeting distance to tumor size was $4.6 \pm 2.2(1.4-8.6)$. The mean effective dose during CT fluoroscopy was $10.1 \pm 8.6 \mathrm{mSv}$ and the mean number of CT fluoroscopy scans $3.1 \pm 2.6$ (0-11 scans; $n=18$ procedures).

\section{Discussion}

CT can be used successfully to guide percutaneous cryoablation of lung, kidney, liver, and bone tumors [4,5,15-19]. It can be used to depict the tumor and surrounding critical structures so that ablation applicators can be placed safely and effectively. Unlike heat-based technologies, the iceball produced during cryoablation produces a well-demarcated region of hypoattenuation. Thus the growth of the iceball can be monitored with CT. While monitoring with serial CT scans allows the interventional radiologist to maximize the chance of freezing the entire tumor, while minimizing the risk of injury to adjacent structures, these CT scans contribute to radiation dose.

Although patient exposures from diagnostic CT scans has received much attention [20], radiation dose to patients undergoing $\mathrm{CT}$ interventional procedures has received little attention $[9,10]$. We estimated the mean effective dose of a CT-guided percutaneous liver cryoablation procedure to be $72 \pm 18 \mathrm{mSv}$. For comparison, we estimated the effective dose of a typical diagnostic abdominal-pelvic CT scan $(120 \mathrm{kVp}, 200$ effective mAs, $24 \times 1.2$ $\mathrm{mm}$ collimation) on the same scanner used in this study to be $8.9 \mathrm{mSv}$. Therefore, the mean effective dose to patients undergoing CT-guided cryoablation procedures $(72 \mathrm{mSv})$ was comparable to approximately eight diagnostic abdominal CT scans. Thus, percutaneous CTguided cryoablation can potentially lead to relatively high radiation doses.

Our result of $72 \mathrm{mSv}$ is high when compared to effective doses for several vascular interventional procedures including abdominal angiograms (mean $12 \mathrm{mSv}$; range: 4-48) and coronary angioplasty (mean $7 \mathrm{mSv}$; range: 2-15.8) [21]. Also, our result is more than double the effective dose of CT-guided RF ablation of liver tumors $(35.3 \mathrm{mSv})$ reported by Tsalafoutas et al. [9]. One possible explanation for this difference may be that the targeting phase of our cryoablation procedures included more applicator placements than what is needed during RF ablation procedures. For example, we typically placed three separate 17 gauge applicators to cryoablate a $2 \mathrm{~cm}$ tumor. Tsalafoutas et al. did not report the mean number of RF applicators, nor did they report tumor size or applicator type used in their ablation procedures [9]. However, in general, only one 17 gauge applicator is needed to RF ablate a $2 \mathrm{~cm}$ tumor [22]. Some RF devices are designed as a single applicator with a deployable array of tines or as a cluster of three applicators placed simultaneously. These RF applicators each alone may produce ablation zones of $4 \mathrm{~cm}$ or greater in diameter. Similar ablation volumes with cryoablation may require sequential placement of four or more applicators. A second reason why effective doses of CT-guided cryoablation were higher than the doses reported of CT-guided RF ablation is the use of CT to monitor iceball growth during cryoablation. Whereas $\mathrm{CT}$ is less useful in monitoring the RF ablation zone, $\mathrm{CT}$ is effective in monitoring the cryoablation zone, and therefore more scans would be expected to be used during cryoablation relative to RF ablation [1-4,16-18,23]. We used CT to image the iceball every $3 \mathrm{~min}$; one way to reduce dose would be to scan less frequently during monitoring when there are no nearby critical structures. Although scanning to monitor the ablation did contribute to the effective dose, most of the dose was incurred during targeting.

More than 50\% of the CT scans were acquired during targeting, and the number of CT scans was the only significant procedural factor contributing to radiation dose. Thus, minimizing the number of scans during targeting would have the greatest impact on radiation dose reduction. This can be accomplished by improving the radiologists' ability to target. Real- 
time navigation devices are being developed for abdominal intervention, including the liver, and are beginning to be used clinically [24,25]. These devices allow interventional radiologists to navigate using pre-procedural volumetric $\mathrm{CT}$ data that approximates the patient's anatomy. Such devices may reduce the number of targeting attempts and therefore the number of scans acquired during the intervention $[24,25]$.

Although other factors had less impact on dose, they too could be used to reduce dose. For example, since our CT fluoroscopy scans were obtained with low dose techniques, greater utilization of short CT fluoroscopy scans instead of conventional CT scans during targeting would reduce dose [26,27]. However, the reduction in radiation dose can be offset if the CT fluoroscopy scans are long, frequent, or performed with higher tube current or voltage. Use of CT-fluoroscopy did not reduce radiation dose in our study, most likely because it was not used enough to affect the mean effective dose for the study population. Nevertheless, if several scans are needed to target a lesion during ablation, use of short, intermittent low dose CT fluoroscopy scans in lieu of short, conventional CT scans will help reduce radiation exposure to patients. Also, radiation dose to patients may be reduced by scanning less frequently during the monitoring phase if adjacent critical structures are at safe distances from the ablation volume.

Since the effective dose of CT-guided cryoablation was substantial, MRI or ultrasonography (US) can be considered as alternative image-guidance modalities to reduce effective dose since they avoid ionizing radiation exposure entirely $[2,3]$. When performing cryoablation, MRI has been reported to be effective in delineating the iceball, separate from the tumor in near real time, and in multiple planes $[1,23]$. US has some utility for targeting or monitoring cryoablation but is less effective in depicting the entire tumor and iceball in part due to acoustic shadowing by the iceball, that prevents visualizing the entire iceball and structures behind it [23]. Nevertheless, US could be used in the CT suite initially to guide the placement of cryoablation applicators; CT could subsequently be used to monitor the iceball formation.

The study population was small but sufficient to study the effective dose incurred during the CT-guided cryoablation of a solitary liver tumor. By limiting the study to single liver mass ablation procedures, we were able to study the effect of other procedure-related factors on dose. All cryoablation procedures reported in this study were performed in a teaching hospital. The involvement of trainees during portions of these procedures may have had an impact to increase radiation dose.

Effective dose was used to estimate the radiation dose. Effective dose is limited in that it does not provide a measure of dose to an individual patient, to individual internal organs nor to the skin. It does not account for age, gender, or specific organ-weighted radiosensitivities. Also, while the DLP-to-effective dose conversion factor of $0.015 \mathrm{mSv} / \mathrm{mGy}-\mathrm{cm}$ used in this report is consistent with Bongartz, other more recent values have been reported in the range of 0.016-0.018 [12]. However, in a retrospective study such as ours, effective dose does provide a reference value for this procedure and its phases; and could be used to compare with future ablation studies that use different protocols.

\section{Conclusion}

The effective radiation dose of CT-guided cryoablation of liver tumors can be substantial. Awareness of the potential radiation dose to patients undergoing CT-guided cryoablation warrants consideration of dose reduction strategies. Reducing the number of procedural scans as proposed in this report is likely to have the greatest impact on dose reduction. 


\section{Acknowledgments}

The authors acknowledge the assistance of Richard Nawfel, MS in this work.

\section{References}

[1]. Silverman SG, Tuncali K, Adams DF, et al. MR imaging-guided percutaneous cryotherapy of liver tumors: initial experience. Radiology. 2000; 217(3):657-64. [PubMed: 11110925]

[2]. Mala T, Edwin B, Tillung T, Kristian Hol P, Soreide O, Gladhaug I. Percutaneous cryoablation of colorectal liver metastases: potentiated by two consecutive freeze-thaw cycles. Cryobiology. 2003; 46(1):99-102. [PubMed: 12623032]

[3]. Dohi M, Harada J, Mogami T, Fukuda K, Toyama Y, Kashiwagi H. MR-guided percutaneous cryotherapy of malignant liver tumor under horizontal-magnetic open system: initial experience. J Hepatobiliary Pancreat Surg. 2003; 10(5):360-5. [PubMed: 14598136]

[4]. Xu KC, Niu LZ, He WB, Hu YZ, Zuo JS. Percutaneous cryosurgery for the treatment of hepatic colorectal metastases. World J Gastroenterol. 2008; 14(9):1430-6. [PubMed: 18322961]

[5]. Callstrom MR, Charboneau JW. Technologies for ablation of hepatocellular carcinoma. Gastroenterology. 2008; 134(7):1831-5. [PubMed: 18486619]

[6]. Choi D, Lim HK, Rhim H, et al. Percutaneous radiofrequency ablation for early-stage hepatocellular carcinoma as a first-line treatment: long-term results and prognostic factors in a large single-institution series. Eur Radiol. 2007; 17(3):684-92. [PubMed: 17093964]

[7]. Choi D, Lim HK, Rhim H, et al. Percutaneous radiofrequency ablation for recurrent hepatocellular carcinoma after hepatectomy: long-term results and prognostic factors. Ann Surg Oncol. 2007; 14(8):2319-29. [PubMed: 17522947]

[8]. Kim SH, Lim HK, Kim MJ, Choi D, Rhim H, Park CK. Radiofrequency ablation of high-grade dysplastic nodules in chronic liver disease: comparison with well-differentiated hepatocellular carcinoma based on long-term results. Eur Radiol. 2008; 18(4):814-21. [PubMed: 18080127]

[9]. Tsalafoutas IA, Tsapaki V, Triantopoulou C, Gorantonaki A, Papailiou J. CT-guided interventional procedures without CT-fluoroscopy assistance: patient effective dose and absorbed dose considerations. Am J Roentgenol. 2007; 188(6):1479-84. [PubMed: 17515365]

[10]. Tsapaki V, Triantopoulou C, Maniatis P, Kottou S, Tsalafoutas J, Papailiou J. Patient skin dose assessment during CT-guided interventional procedures. Radiat Prot Dosimetry. 2008; 129(1-3): 29-31. [PubMed: 18326886]

[11]. Bongartz, G.; Golding, SJ.; Jurik, GA., et al. European guidelines on quality criteria for computed tomography. European Commission; Brussels, Belgium: 1999.

[12]. Bongartz, G.; Golding, SJ.; Jurik, GA., et al. European Guidelines for Multislice Computed Tomography: Appendix A. European Commission; 2004. Contract No. FIGM-CT2000-20078CT-TIP

[13]. Huda W, Ogden KM, Khorasani MR. Converting dose-length product to effective dose at CT. Radiology. 2008; 248(3):995-1003. [PubMed: 18710988]

[14]. Erturk SM, Silverman S, Mortele K, et al. Percutaneous biopsy of abdominal masses using 25gauge needles. Abdom Imaging. 2010; 35(1):70-4. [PubMed: 19093067]

[15]. Georgiades CS, Hong K, Bizzell C, Geschwind JF, Rodriguez R. Safety and efficacy of CTguided percutaneous cryoablation for renal cell carcinoma. J Vasc Interv Radiol. 2008; 19(9): 1302-10. [PubMed: 18725093]

[16]. Gupta A, Allaf ME, Kavoussi LR, et al. Computerized tomography guided percutaneous renal cryoablation with the patient under conscious sedation: initial clinical experience. J Urol. 2006; 175(2):447-52. [discussion 52-3]. [PubMed: 16406968]

[17]. Littrup PJ, Ahmed A, Aoun HD, et al. CT-guided percutaneous cryotherapy of renal masses. J Vasc Interv Radiol. 2007; 18(3):383-92. [PubMed: 17377184]

[18]. Wang H, Littrup PJ, Duan Y, Zhang Y, Feng H, Nie Z. Thoracic masses treated with percutaneous cryotherapy: initial experience with more than 200 procedures. Radiology. 2005; 235(1):289-98. [PubMed: 15798173] 
[19]. Callstrom MR, Atwell TD, Charboneau JW, et al. Painful metastases involving bone: percutaneous image-guided cryoablation - prospective trial interim analysis. Radiology. 2006; 241(2):572-80. [PubMed: 17057075]

[20]. Kalra MK, Maher MM, Toth TL, et al. Strategies for CT radiation dose optimization. Radiology. 2004; 230(3):619-28. [PubMed: 14739312]

[21]. Mettler FA Jr, Huda W, Yoshizumi TT, Mahesh M. Effective doses in radiology and diagnostic nuclear medicine: a catalog. Radiology. 2008; 248(1):254-63. [PubMed: 18566177]

[22]. Zagoria RJ, Traver MA, Werle DM, Perini M, Hayasaka S, Clark PE. Oncologic efficacy of CTguided percutaneous radiofrequency ablation of renal cell carcinomas. Am J Roentgenol. 2007; 189(2):429-36. [PubMed: 17646471]

[23]. Morrison PR, Silverman SG, Tuncali K, Tatli S. MRI-guided cryotherapy. J Magn Reson Imaging. 2008; 27(2):410-20. [PubMed: 18219676]

[24]. Banovac F, Tang J, Xu S, et al. Precision targeting of liver lesions using a novel electromagnetic navigation device in physiologic phantom and swine. Med Phys. 2005; 32(8):2698-705. [PubMed: 16193801]

[25]. Crocetti L, Lencioni R, Debeni S, See TC, Pina CD, Bartolozzi C. Targeting liver lesions for radiofrequency ablation: an experimental feasibility study using a CT-US fusion imaging system. Invest Radiol. 2008; 43(1):33-9. [PubMed: 18097275]

[26]. Carlson SK, Bender CE, Classic KL, et al. Benefits and safety of CT fluoroscopy in interventional radiologic procedures. Radiology. 2001; 219(2):515-20. [PubMed: 11323481]

[27]. Silverman SG, Tuncali K, Adams DF, Nawfel RD, Zou KH, Judy PF. CT fluoroscopy-guided abdominal interventions: techniques, results, and radiation exposure. Radiology. 1999; 212(3): 673-81. [PubMed: 10478231] 


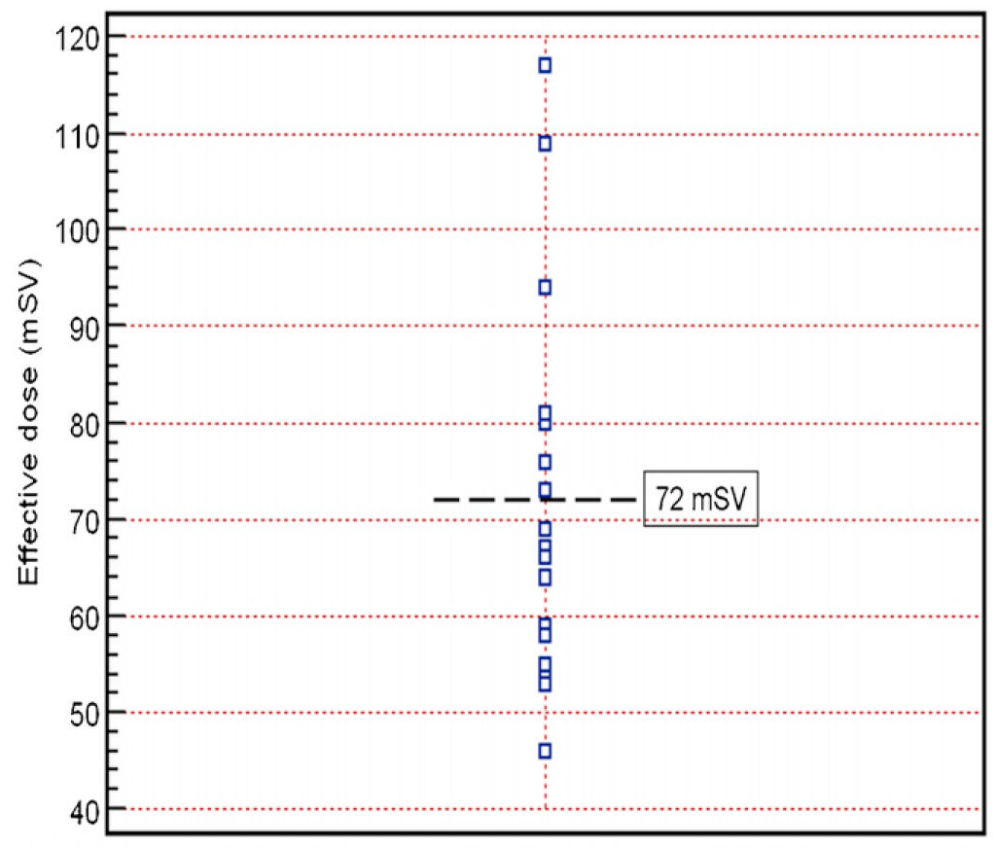

CT-guided cryoablation procedures $(n=20)$

Fig. 1.

Effective doses of CT-guided liver cryoablation procedures $(n=20)$. The graph illustrates the distribution of effective dose during CT-guided cryoablation procedures. Each square represents an effective dose for a procedure. The black dotted line indicates the mean effective dose. 


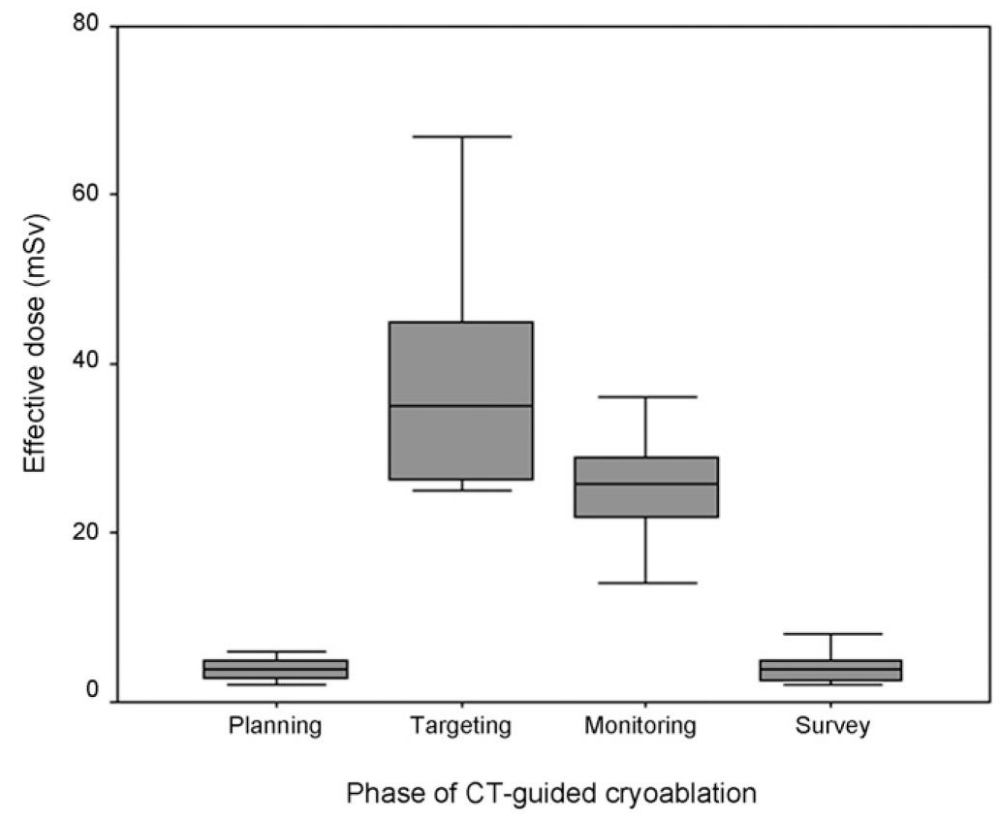

Fig. 2.

Box plot compares effective dose during each phase of CT-guided liver cryoablation procedures. The mean effective dose was highest during targeting followed by monitoring ( $p$ $<0.05)$. However, there was no significant difference between planning and post-ablation survey phases $(p>0.05)$. Horizontal line within the box indicates median value. The median values are $4 \mathrm{mSv}$ for planning phase, $35 \mathrm{mSv}$ for targeting phase, $26 \mathrm{mSv}$ for monitoring phase, and $4 \mathrm{mSv}$ for post-ablation survey phase. 


\section{Table 1}

Mean dose length product and effective dose during CT-guided percutaneous cryoablation of liver tumors ( $n=$ 20).

\begin{tabular}{lccccc}
\hline \multirow{2}{*}{ Procedural phases } & \multicolumn{2}{c}{ Dose length product $(\mathbf{m G y *} \mathbf{c m})$} & & \multicolumn{2}{c}{ Effective dose $(\mathbf{m S v})$} \\
\cline { 2 - 3 } \cline { 5 - 6 } & Mean \pm SD & Range & & Mean \pm SD & Range \\
\hline Planning & $322 \pm 150$ & $138-681$ & $4.8 \pm 2.2$ & $2-10$ \\
Targeting & $2496 \pm 843$ & $1662-4492$ & $37.5 \pm 12.5$ & $25-67$ \\
Monitoring & $1706 \pm 454$ & $937-2825$ & $25.5 \pm 6.8$ & $14-42$ \\
Post-ablation survey & $273 \pm 123$ & $135-548$ & $4.1 \pm 1.9$ & $2-8$ \\
Entire procedure & $4796 \pm 1214$ & $3059-7784$ & $72 \pm 18$ & $46-117$ \\
\hline
\end{tabular}

Note: SD, standard deviation. Dose length product and effective dose for each phase were significantly different from each other $(p<0.0001)$ except for the planning and post-ablation survey phases $(p>0.05)$. 


\section{Table 2}

Contribution (percent) to effective dose and to total number of scans from each phase during CT-guided cryoablation of liver tumors.

\begin{tabular}{|c|c|c|c|c|}
\hline \multirow[t]{2}{*}{ Procedural phases } & \multicolumn{2}{|l|}{ Effective dose } & \multicolumn{2}{|l|}{ Number of scans } \\
\hline & $\operatorname{Mean} \pm \operatorname{SD}(\%)$ & Range (\%) & $\operatorname{Mean} \pm \operatorname{SD}(\%)$ & Range (\%) \\
\hline Planning & $6.7 \pm 3.1$ & $3-15$ & $4.2 \pm 2.3$ & $2.3-11.1$ \\
\hline Targeting & $51.3 \pm 7.5$ & $38-70$ & $53.8 \pm 6.5$ & $36.8-65.9$ \\
\hline Monitoring & $35.9 \pm 7.2$ & $24-48$ & $37.9 \pm 6.7$ & $26.0-52.6$ \\
\hline Post-ablation survey & $6.0 \pm 2.8$ & $2-14$ & $4.1 \pm 3.2$ & $2.3-17.4$ \\
\hline
\end{tabular}

Note: SD, standard deviation. The mean percent contribution of effective dose and the mean number of scans for each phase were significantly different from each other $(p<0.0001)$ except for the planning and post-ablation survey phases $(p>0.05)$ 